University of Nebraska - Lincoln

DigitalCommons@University of Nebraska - Lincoln

\title{
Effect of combined metal-carbon additions on the microstructure and structure of Sm2Fe17
}

\author{
B. E. Meacham \\ University of Utah \\ Jeffrey E. Shield \\ University of Nebraska-Lincoln, jshield@unl.edu
}

Follow this and additional works at: https://digitalcommons.unl.edu/mechengfacpub

Part of the Mechanical Engineering Commons

\footnotetext{
Meacham, B. E. and Shield, Jeffrey E., "Effect of combined metal-carbon additions on the microstructure and structure of Sm2Fe17" (2003). Mechanical \& Materials Engineering Faculty Publications. 28. https://digitalcommons.unl.edu/mechengfacpub/28

This Article is brought to you for free and open access by the Mechanical \& Materials Engineering, Department of at DigitalCommons@University of Nebraska - Lincoln. It has been accepted for inclusion in Mechanical \& Materials Engineering Faculty Publications by an authorized administrator of DigitalCommons@University of Nebraska Lincoln.
} 


\title{
Effect of combined metal-carbon additions on the microstructure and structure of $\mathrm{Sm}_{2} \mathrm{Fe}_{17}$
}

\author{
B.E. Meacham ${ }^{\text {a) }}$ \\ Department of Materials Science and Engineering, University of Utah, Salt Lake City, Utah 84112 \\ J.E. Shield \\ Department of Mechanical Engineering, University of Nebraska, Lincoln, Nebraska 68588
}

(Received 15 July 2002; accepted 18 October 2002)

\begin{abstract}
The effect of combined alloying additions on the structure and scale of rapidly solidified $\mathrm{Sm}-\mathrm{Fe}$ alloys was investigated. Transition metal additions tend to promote the formation of the disordered $\mathrm{TbCu}_{7}$-type structure in $\mathrm{Sm}_{2} \mathrm{Fe}_{17}$ alloys, as determined by monitoring the long-range order parameter. Essentially no order was observed for $\mathrm{M}=\mathrm{Ti}, \mathrm{Zr}, \mathrm{V}$, or $\mathrm{Nb}$. Thus, the structure was close to the prototypical $\mathrm{TbCu}_{7}$-type structure. With $\mathrm{M}=\mathrm{Si}$, a large amount of order was observed $(\mathrm{S}=0.62)$, resulting in a structure closer to the well-ordered $\mathrm{Th}_{2} \mathrm{Zn}_{17}$-type. The microstructural scale was also affected by alloying. In this case, refinement depended on the substituent and also on carbon for microstructural refinement. The scale of the as-solidified grain structures ranged from $100 \mathrm{~nm}$ for $\mathrm{SiC}$-modified alloys to $13 \mathrm{~nm}$ for NbC-modified alloys. The degree of refinement was directly related to the atomic size of the M addition.

The refinement was the result of solute partitioning to grain boundaries, resulting in a solute drag effect that lowered the growth rates.
\end{abstract}

\section{INTRODUCTION}

The microstructure and atomic structure combine to critically influence the magnetic behavior of materials. The atomic structure-the size, shape, and atomic configuration of the unit cell-is associated with intrinsic properties such as the saturation magnetization and magnetocrystalline anisotropy. The microstructure-the grain size, morphology, and uniformity-often affects the demagnetization process. It is important, then, to carefully control the microstructural evolution and structural state during processing. Routinely, this is done through alloy design.

In the interstitial Sm-Fe-based permanent magnets, the structural state is critically dependent on the processing conditions and alloy composition. While the equilibrium compound is the $\mathrm{Th}_{2} \mathrm{Zn}_{17}$-type $\mathrm{Sm}_{2} \mathrm{Fe}_{17}$ structure, the $\mathrm{TbCu}_{7}$-type $\mathrm{SmFe}_{7}$ has also been observed after rapid solidification or upon a ternary alloying. ${ }^{1-9}$ The $\mathrm{SmFe}_{7}$ and $\mathrm{Sm}_{2} \mathrm{Fe}_{17}$ structures are related by an order/disorder transformation involving the transition metal dumbbell sites; in the $\mathrm{Sm}_{2} \mathrm{Fe}_{17}$ structure, the $\mathrm{Fe}-\mathrm{Fe}$ dumbbells are ordered, while in the $\mathrm{SmFe}_{7}$ structure they are placed randomly on the lattice. The amount of long-range order can be controlled through processing, allowing the structural state to be carefully controlled. ${ }^{10-12}$ Specific site substitution preference also can

\footnotetext{
a) Present address: Metals and Ceramics Division, Idaho National Engineering Laboratory, Idaho Falls, Idaho 83415.
}

alter the intrinsic magnetic properties, ${ }^{13}$ and this is also affected by specific alloying additions and synergistic effects.

The microstructural evolution in Sm-Fe-based alloys is also affected by the processing and alloying characteristics. Combined TiC additions were found to effectively refine the grain size ${ }^{14,15}$ and improved the glass formability. ${ }^{16}$ Other additions, including $\mathrm{Ga}^{17}$ and $\mathrm{Ga}$ with $\mathrm{Nb}, \mathrm{Cu}$ or $\mathrm{Zr}$, all in combination with $\mathrm{C},{ }^{9}$ have also effectively refined the grain size. Because of the overarching influence that alloying elements have on both intrinsic and extrinsic properties of permanent magnets, a better understanding of the roles specific additions have on the microstructural and structural formation in $\mathrm{Sm}-\mathrm{Fe}$ alloys is desirable. Furthermore, it is desirable to understand in general the microstructural development in materials. For example, different transition metal substitutions can occupy different crystallographic sites, with a concomitant influence on magnetic properties. ${ }^{13,18}$ Similarly, the effect of additions on the microstructural development can depend on both liquid and solid solubility. ${ }^{19}$ In this paper, we examine the roles that various alloying elements, in combination with $\mathrm{C}$, have on the microstructure and structure of Sm-Fe alloys to understand the controlling mechanism for microstructural refinement.

\section{EXPERIMENTAL}

Samples with the nominal compositions of $\left(\mathrm{Sm}_{0.11} \mathrm{Fe}_{0.89}\right)_{94} \mathrm{M}_{3} \mathrm{C}_{3}$, with $\mathrm{M}=\mathrm{Si}, \mathrm{V}, \mathrm{Zr}, \mathrm{Nb}$, and $\mathrm{Ti}$ were alloyed by arc melting high-purity elemental 
constituents in an ultra-high-purity Ar atmosphere. These ingots were then rapidly solidified by melt spinning in $1 \mathrm{~atm}$ Ar with a tangential wheel velocity of $30 \mathrm{~m} / \mathrm{s}$. To compensate for $\mathrm{Sm}$ vaporization during the melting process, $5 \%$ excess $\mathrm{Sm}$ was added to the initial elemental mix. Weight loss after arc melting, as well as chemical analysis by inductively coupled plasma/Auger electron spectroscopy (ICP/AES) revealed that the Sm:Fe ratios for all samples were close to 2:17.

The samples were characterized by x-ray diffraction (XRD) utilizing a Philips X'Pert MPD (Eindhoven, the Netherlands) system with lightly powdered samples mounted on an off-cut $\mathrm{SiO}_{2}$ single crystal to essentially eliminate diffraction effects from the sample holder. The order parameters $(S)$ were calculated by comparing the integrated intensities of $\{00 \cdot 3\}$ superlattice peaks with $\{02.4\}$ fundamental peaks in the equation

$$
S^{2}=\frac{I_{\mathrm{s}}\left|F_{\mathrm{f}}\right|^{2} \rho_{\mathrm{f}} L P_{\mathrm{f}}}{I_{\mathrm{f}}\left|F_{\mathrm{s}}\right|^{2} \rho_{\mathrm{s}} L P_{\mathrm{s}}},
$$

where $F$ is the structure factor for each peak, $\rho$ is the multiplicity, and $L P$ is the Lorentz Polarization factor. The structure factors were calculated considering the atomic positions of the $\mathrm{Sm}_{2} \mathrm{Fe}_{17}$ provided by the Atlas of Crystal Structure Types for Intermetallic Phases, ${ }^{20}$ and the structure factor forms from the International Tables for Crystallography. ${ }^{21}$ The integrated intensities $I_{\mathrm{f}}$ and $I_{\mathrm{s}}$ were determined through curve fitting routines using a modified Gaussian peak shape, which provided the best fit parameters of the various models examined.

Microstructural analysis was accomplished by transmission electron microscopy (TEM) with a JEOL 2000FXII (Tokyo, Japan). Ribbon samples were mounted on $\mathrm{Cu}$ slotted grids and then perforated by coldstage ion milling on a Gatan Duomill (Warrendale, PA) at $4.5 \mathrm{kV}$. Perforation typically was accomplished in approximately $8 \mathrm{~h}$ of milling. The grain sizes were measured from TEM micrographs by the line intercept method.

Differential thermal analysis (DTA) was used to determine the thermal behavior of the various alloys and specifically to determine the presence and crystallization characteristics of amorphous phase. A Perkin-Elmer System 7 DTA (Shelton, CT) was used for this analysis. The magnetic measurements were accomplished with a Lakeshore (Westerville, $\mathrm{OH}$ ) vibrating sample magnetometer after pulse magnetization in a field of $35 \mathrm{kOe}$.

\section{RESULTS}

The ordered and disordered structures are differentiated by diffraction peaks that arise due to the ordering of the dumbbell atoms. The differences are illustrated in the
XRD scans of Fig. 1. With $\mathrm{M}=\mathrm{Si}$, there are welldefined superlattice peaks associated with the ordered $\mathrm{Th}_{2} \mathrm{Zn}_{17^{-}}$-type structure (notably the $\{02.4\}$ at $2 \theta \sim 38^{\circ}$, the shoulder prior to the $\{30 \cdot 3\}$, and the $\{00 \cdot 6\})$. For the other alloys, these peaks are absent, indicating the lack of long-range order that makes the structure closer to the $\mathrm{TbCu}_{7}$-type structure. The degree of order was quantified by comparing the intensity of the $\{02.4\}$ superlattice peak with the intensity of the $\{30.0\}$ fundamental peak according to Eq. (1), which provides the long-range order parameter $S$. This allows a more accurate description of the structure. The value of $S$ determined for each sample is shown in Table I. For $\mathrm{M}=\mathrm{V}, \mathrm{Zr}$, and $\mathrm{Nb}$, no superlattice peak was detected, resulting in $S=0$ for these alloys. For $\mathrm{M}=\mathrm{Ti}$, weak ordering $(S=0.22)$ was detected, while relatively strong ordering $(S=0.62)$ was observed for $\mathrm{M}=\mathrm{Si}$. For $\mathrm{M}=\mathrm{Si}$, the ordering was greater than that detected in the binary alloy under similar solidification conditions $(S=0.44)$. Additionally, the XRD patterns reveal some fraction of amorphous phase in several of the alloys, most noticeably in $\mathrm{M}=\mathrm{Nb}$ and $\mathrm{Zr}$. Again, the amorphous phase fraction appears in the heavier $\mathrm{M}$ additions.

DTA corroborated the XRD data, revealing the presence of amorphous phase for $\mathrm{M}=\mathrm{Nb}$ and $\mathrm{Zr}$, as well as for $\mathrm{M}=\mathrm{V}$ and Ti. Crystallization characteristics are shown in Table I for the various alloys. The crystallization enthalpy $\Delta_{a \rightarrow x}$ is a reflection of the amount of amorphous phase present in the as-solidified material, with higher values indicating more amorphous phase crystallizing (Table I). The crystallization temperature, a measure of the glass stability, in general scales with atomic number, although for $\mathrm{M}=\mathrm{V}$ it is anomalously low. Thus, the alloying addition $M$ strongly influences the structure and phase formation in $\mathrm{Sm}-\mathrm{Fe}-\mathrm{M}-\mathrm{C}$ alloys.

The addition of combined $\mathrm{M}$ and $\mathrm{C}$ to $\mathrm{Sm}-\mathrm{Fe}$ alloys significantly altered the solidification microstructure as well. While the as-solidified binary Sm-Fe alloy was

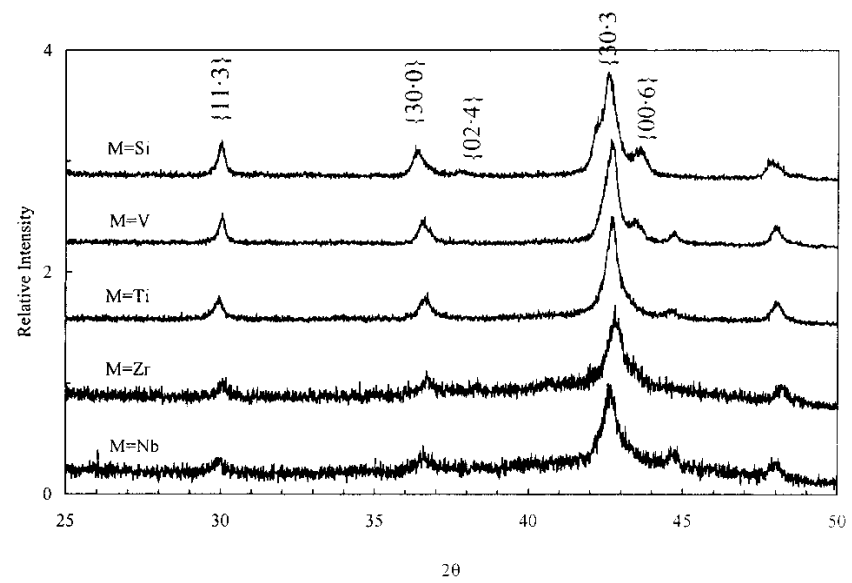

FIG. 1. XRD patterns of $\left(\mathrm{Sm}_{0.11} \mathrm{Fe}_{0.89}\right)_{94} \mathrm{M}_{3} \mathrm{C}_{3}$ alloys with $\mathrm{M}=\mathrm{Si}$, $\mathrm{Ti}, \mathrm{V}, \mathrm{Zr}$ and $\mathrm{Nb}$. 
observed to have a coarse microstructure on the order of $500 \mathrm{~nm}$, the alloying additions resulted in grain refinement. With $\mathrm{M}=\mathrm{Si}$ the grain size was observed to be on the order of $100 \mathrm{~nm}$ (Fig. 2). Other additions had a more profound effect on the microstructural scale, with the average grain size reaching $13 \mathrm{~nm}$ for $\mathrm{M}=\mathrm{Nb}$ (Fig. 2). The grain size determined for each of the alloys is summarized in Table I. Additionally, the grain morphology became more equiaxed with the addition of the combined $\mathrm{MC}$ additions.

TABLE I. Long-range order parameter, crystallization parameters, and grain size observed for the as-solidified $\left(\mathrm{Sm}_{0.89} \mathrm{Fe}_{0.11}\right)_{94} \mathrm{M}_{3} \mathrm{C}_{3}$ alloys.

\begin{tabular}{lcccc}
\hline \hline & $\begin{array}{c}\text { Long-range } \\
\text { order parameter } S\end{array}$ & $\begin{array}{c}\text { Crystallization } \\
\text { temperature } \\
(\mathrm{K})\end{array}$ & $\begin{array}{c}\text { Crystallization } \\
\text { enthalpy } \\
(\mathrm{J} / \mathrm{g})\end{array}$ & $\begin{array}{c}\text { Grain size } \\
(\mathrm{nm})\end{array}$ \\
\hline $\mathrm{Si}$ & 0.62 & $\ldots$ & $\ldots$ & 100 \\
$\mathrm{Ti}$ & 0.22 & 837 & -21.3 & 57 \\
$\mathrm{~V}$ & 0 & 810 & -17.7 & 51 \\
$\mathrm{Zr}$ & 0 & 854 & -19.9 & 27 \\
$\mathrm{Nb}$ & 0 & 864 & -30.7 & 13 \\
\hline \hline
\end{tabular}

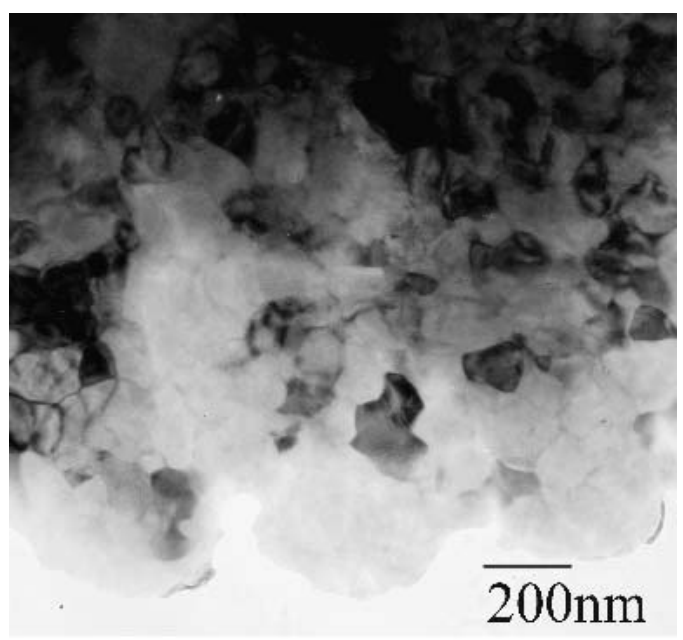

(a)

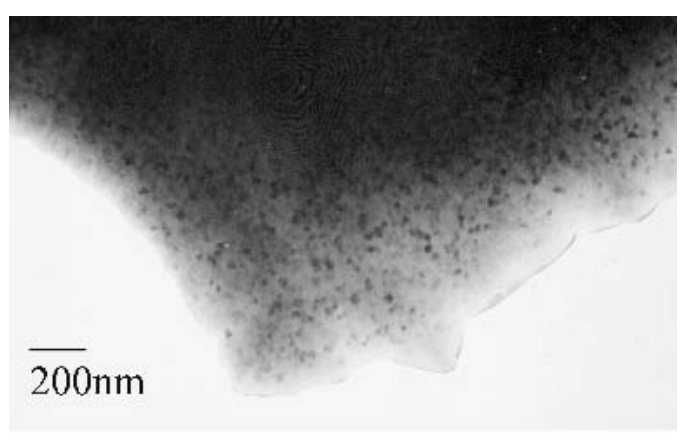

(b)

FIG. 2. TEM bright field micrographs of (a) $\left(\mathrm{Sm}_{0.11} \mathrm{Fe}_{0.89}\right){ }_{94} \mathrm{Si}_{3} \mathrm{C}_{3}$. and (b) $\left(\mathrm{Sm}_{0.11} \mathrm{Fe}_{0.89}\right)_{94} \mathrm{Nb}_{3} \mathrm{C}_{3}$.
The combined role of the $\mathrm{M}$ and $\mathrm{C}$ additions on the structural and microstructural evolution in $\mathrm{Sm}-\mathrm{Fe}$ alloys at the $\mathrm{Sm}_{2} \mathrm{Fe}_{17}$ composition was investigated by examining a series of $\left(\mathrm{Sm}_{0.89} \mathrm{Fe}_{0.11}\right)_{97-x} \mathrm{Ti}_{3} \mathrm{C}_{x}$ alloys, with $x$ varying from 0 to 6 . Of particular interest were the variation of the long-range order parameter $S$ and grain size with $x$. The phase formation, as determined by XRD, was observed to be similar to the previous alloys. The long-range order parameter $S$, which reflects the structural change from the $\mathrm{Th}_{2} \mathrm{Zn}_{17}$-type structure $(S=1)$ to a $\mathrm{TbCu}_{7}$-type structure $(S=0)$, was observed to be very low $(\mathrm{S} \sim 0.1$ to 0.4$)$ and relatively independent of $x$ (Fig. 3). The scatter is most likely due to the difficulty in determining $S$ for these mostly disordered materials because of the extremely weak superlattice peaks. Some differences, however, might arise due to the fact that $\mathrm{Ti}$ site occupancy is different for carburized and uncarburized samples, and for different $\mathrm{C}$ concentrations. ${ }^{22,23}$ The independence of $S$ with $x$ implies that Ti (or, in general, $\mathrm{M})$ plays the critical role in creating $\mathrm{Fe}-\mathrm{Fe}$ dumbbell disorder, leading to the $\mathrm{TbCu}_{7}$-type structure, in $\mathrm{Sm}-\mathrm{Fe}$ and related structures.

The microstructural scale, however, was observed to strongly depend on the value of $x$. At $x=0$, the grain size was observed to be approximately $500 \mathrm{~nm}$, which is on the order of the grain size observed in the binary alloy. The addition of carbon, however, led to significant refinement, ultimately reaching a grain size close to $50 \mathrm{~nm}$ for $x=6$ (Fig. 4).

\section{DISCUSSION}

We have shown that combined $\mathrm{M}$ and $\mathrm{C}$ additions significantly affect the structural state and microstructural scale of $\mathrm{Sm}-\mathrm{Fe}$ alloys. The development of longrange order of the transition metal dumbbell sites is

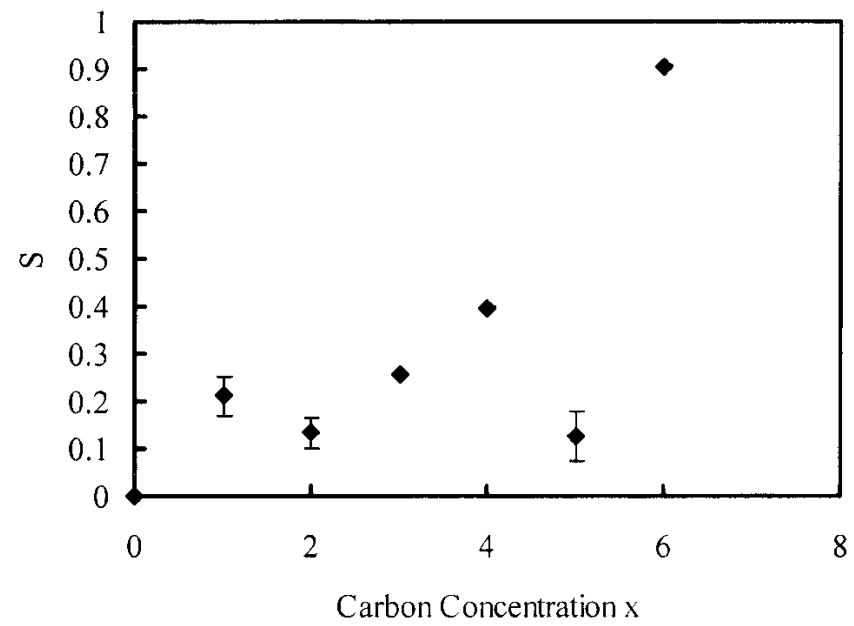

FIG. 3. Long-range order parameter as a function of $\mathrm{C}$ content for $\left(\mathrm{Sm}_{0.89} \mathrm{Fe}_{0.11}\right)_{97-x} \mathrm{Ti}_{3} \mathrm{C}_{x}$. 
primarily affected by the $\mathrm{M}$ addition. Si only minimally reduces the long-range order parameter $S$, while the transition metals essentially eliminate the development of long-range order. $\mathrm{Ti}$ and $\mathrm{V}$ have been observed to substitute primarily on the $\mathrm{Fe} 6(c)$ site (the dumbbell site), while $\mathrm{Nb}$ and $\mathrm{Zr}$ split between the $\mathrm{Fe} 6(c)$ and $18(f)$ sites. ${ }^{18}$ Si strongly prefers the Fe $18(h)$ site. ${ }^{24}$ Site preference for transition metals alloyed in combination with carbon were found to be more complicated, with site preference split between $6(c), 18(f)$, and $18(h)$ sites. ${ }^{13,22}$ However, the substitution levels in these studies were as much as twice as high, and there may be primary, secondary, etc., site preference hierarchy that has not been investigated. The disruption in long-range order observed in this study is clearly due to $\mathrm{M}$ and is most likely caused by substitution on the dumbbell site [6(c)]. The probable cause is the substitution of the transition metal on an $\mathrm{Fe}$ dumbbell site. The different valence and/or size of the $\mathrm{M}$ ion create an M-vacancy pair. The tendency of $M$ to occupy specific Fe sites, the M/vacancy pairing, and the size of $\mathrm{M}$ all tend to limit its diffusivity. In contrast, $\mathrm{Fe}$ diffusion to form the ordered structure in the simple binary case can occur between any of the different Fe sites in the structure, resulting in more significant diffusivity. A larger $\mathrm{M}$ might be expected to have a more significant impact on the long-range order by inhibiting diffusion during formation. However, in this study the development of long-range order during solidification was essentially eliminated and independent of the atomic size for the transition metals studied $(\mathrm{M}=\mathrm{Ti}, \mathrm{V}, \mathrm{Zr}$, and $\mathrm{Nb})$. More detailed work under varying solidification conditions is necessary to clarify this point. Si does not preferentially occupy an $\mathrm{Fe}$ dumbbell site and thus does not disrupt the ordering process. Hence, the $\mathrm{M}=\mathrm{Si}$ alloy is relatively well ordered $(S=0.62)$. This confirms that substitution on the dumbbell site is critical in reducing long-range order and formation of the $\mathrm{TbCu}_{7}$-type structure.

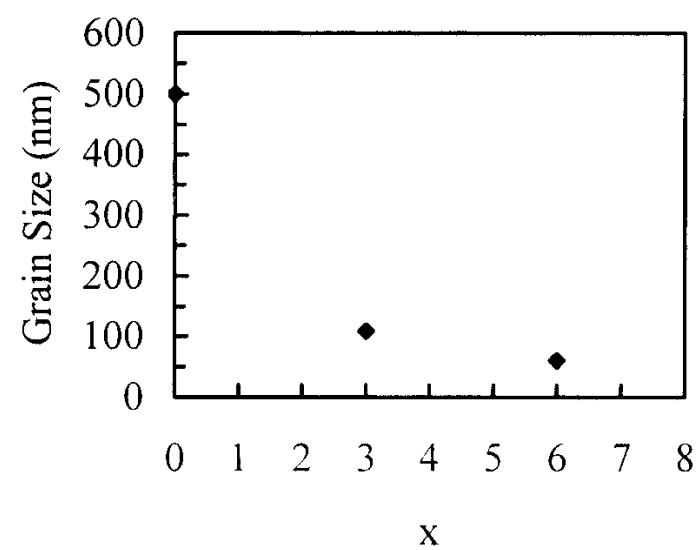

FIG. 4. Grain size as a function of $\mathrm{C}$ content for $\left(\mathrm{Sm}_{0.89} \mathrm{Fe}_{0.11}\right)_{97-x} \mathrm{Ti}_{3} \mathrm{C}_{x}$, as determined from TEM micrographs.
While the reduction of $S$ with the addition of M strongly implies that at least some of the additions remain in solid solution, grain refinement usually does not depend on solid solution formation. Typically, grain refinement relies on changes in the nucleation and/or growth characteristics. In this study, the grain size depends on the atomic size of M (Fig. 4). The reduction in grain size is thought to be caused by reducing the growing solid interface velocity arising from solute segregation. While the Ti addition is similar to reported solubility limits, ${ }^{25}$ the larger-sized additions would most likely have lower solubility. Thus, excess solute must be rejected into the liquid, with the kinetics of this process controlling the grain size. This explains the dependency of the grain size on atomic radius (Fig. 5), as, for example, $\mathrm{Nb}$ would be expected to have the lowest solubility (and thus the most rejected to the interface) and smallest grain size. The critical role of carbon is that it too dissolves into the structure, occupying an interstitial site, which can in turn distort the lattice and limit the solubility of other additions. ${ }^{26}$ The behavior of the $\left(\mathrm{Sm}_{0.89} \mathrm{Fe}_{0.11}\right)_{97-x} \mathrm{Ti}_{3} \mathrm{C}_{x}$ alloys with respect to grain size supports this mechanism as well. At $x=0$, most (or all) of the $\mathrm{Ti}$ is dissolved into solid solution with little effect on the grain size. Carbon as well is dissolved into solution, which, as mentioned, lowers the solubility of Ti. This then leads to more partitioning of Ti (and perhaps C), resulting in significant grain refinement, as was observed. Higher carbon additions further reduced the grain size, again implying more partitioning. The combined presence of $\mathrm{C}$ and $\mathrm{Ti}$ (or generally, $\mathrm{M}$ ) in solid solution would be expected to expand the lattice, which in $\mathrm{Sm}-\mathrm{Fe}$ has profound effects on the magnetic properties. In this case, we observed a sharp increase in coercivity at $x=5$, indicating a transition from planar to uniaxial anisotropy (Fig. 6). It is not clear why uniaxial anisotropy was not achieved earlier, as the solubility limit of $\mathrm{C}$

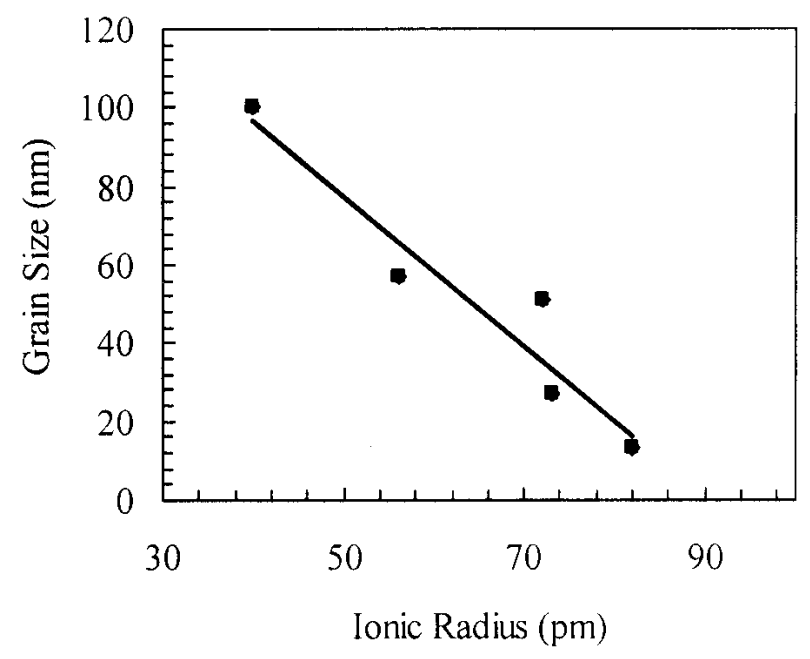

FIG. 5. Grain size as a function of $\mathrm{M}^{4+}$ ion size for $\left(\mathrm{Sm}_{0.11} \mathrm{Fe}_{0.89}\right)_{94} \mathrm{M}_{3} \mathrm{C}_{3}$. 


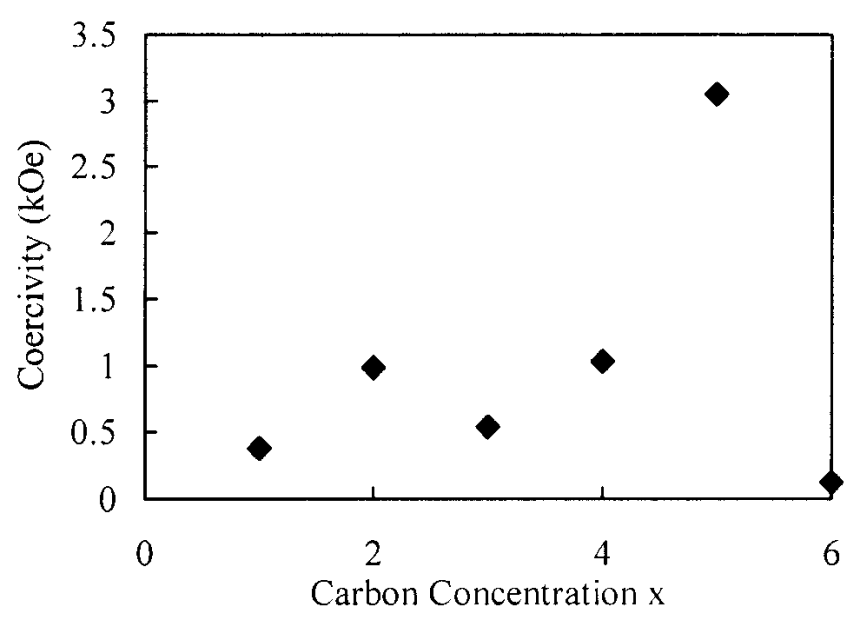

FIG. 6. Coercivity as a function of $x$ for as-solidified $\left(\mathrm{Sm}_{0.89} \mathrm{Fe}_{0.11}\right)_{97-x} \mathrm{Ti}_{3} \mathrm{C}_{x}$ alloys.

in $\mathrm{Sm}_{2} \mathrm{Fe}_{17}$ is between 2 and 3. The extremely low coercivity at $x=6$ is attributed to a soft magnetic glassy phase present in this alloy.

The behavior of the glassy phase appears to be consistent with a reduction in growth rates that arises due to interface drag effects. The amorphous phase component that was observed in the TiC-, VC-, $\mathrm{ZrC}-$, and $\mathrm{NbC}-$ added alloys increases with increasing atomic size of $\mathrm{M}$. The slowed growth of crystallites allows a greater undercooling of the liquid, which in turn can be frozen into the glassy state.

\section{CONCLUSIONS}

In this paper, the combined effect of metal and carbon additions on the structure and scale of Sm-Fe alloys is reported. The transition from the equilibrium $\mathrm{Th}_{2} \mathrm{Zn}_{17^{-}}$ type structure to its disordered structural $\mathrm{TbCu}_{7}$-type derivative was monitored by tracking the long-range order parameter. Upon the addition of the transition metals $\mathrm{V}$, $\mathrm{Zr}$, and $\mathrm{Nb}$, the long-range order parameter was determined to be 0 , indicating the formation of the $\mathrm{TbCu}_{7^{-}}$ type disordered structure; however, for $\mathrm{M}=\mathrm{Si}$ the structure that formed more closely resembled the ordered $\mathrm{Th}_{2} \mathrm{Zn}_{17}$-type structure. Carbon addition did not contribute to the disordering process.

The microstructural scale was also observed to depend on the specific alloying addition. In this case, $\mathrm{C}$ played a critical role, as only modest reductions were observed in its absence. The combined effect of $\mathrm{M}$ and $\mathrm{C}$ in grain refinement was attributed to partitioning of the solute to the solid/liquid interface. The degree of refinement scaled with the size of $\mathrm{M}$, with grain sizes of less than $20 \mathrm{~nm}$ observed for the NbC-modified alloys (in comparison to approximately $500 \mathrm{~nm}$ for simple binary $\mathrm{Sm}-\mathrm{Fe}$ alloys).

\section{ACKNOWLEDGMENTS}

The authors are grateful to Prof. Saskia Duyvesteyn of the University of Utah for her expertise in ICP/AES analysis. The authors are grateful for financial support from the National Science Foundation under Grant Nos. DMR 9714946 and DMR 0296104.

\section{REFERENCES}

1. Y. Xingbo, T. Miyazaki, T. Izumi, H. Saito, and M. Takahashi, IEEE Trans. Magn. 23, 3104 (1987).

2. M. Katter, J. Wecker, and L. Schultz, J. Appl. Phys. 70, 3188 (1991).

3. F.E. Pinkerton and C.D. Fuerst, Appl. Phys. Lett. 60, 2558 (1992).

4. T. Yoneyama, T. Yamamoto, and T. Hidaka, Appl. Phys. Lett. 67, 3197 (1995).

5. J.E. Shield, C.P. Li, and D.J. Branagan, J. Magn. Magn. Mater. 188, 353 (1998).

6. H. Sun, K. Makita, T. Tomida, S. Hirosawa, and Y. Maehara, Phys. Status Solidi A 158, 559 (1996).

7. J.X. Zhang, I. Kleinschroth, Z.H. Cheng, D. Goll, and H. Kronmuller, J. Appl. Phys. 86, 3274 (1999).

8. Z.H. Cheng, J.X. Zhang, H.Q. Guo, J. van Lier, H. Kronmuller, and B.G. Shen, Appl. Phys. Lett. 72, 1110 (1998).

9. H.W. Zhang, S.Y. Zhang, B.G. Shen, and F.W. Wang, J. Magn. Magn. Mater. 187, 247 (1998).

10. B.E. Meacham, D.J. Branagan, and J.E. Shield, J. Appl. Phys. 87, 6707 (2000).

11. B.E. Meacham, J.E. Shield, and D.J. Branagan, IEEE Trans. Magn. 37, 2503 (2001).

12. J.E. Shield, B.B. Kappes, B.E. Meacham, K.W. Dennis, and M.J. Kramer, J. Alloys Compd. (in press).

13. H. Luo, Z. Hu, M. Chen, W.B. Yelon, G.K. Marasinghe, P.C. Ezekwenna, W.J. James, W.C. Chang, and S.H. Tsai, J. Appl. Phys. 81, 4542 (1997).

14. J.E. Shield, D.J. Branagan, C.P. Li, and R.W. McCallum, J. Appl. Phys. 83, 5564 (1998).

15. J.E. Shield, C.P. Li, and D.J. Branagan, J. Magn. Magn. Mater. 188, 353 (1998).

16. J.E. Shield, J. Alloys Compd. 291, 222 (1999).

17. Z.H. Cheng, J.X. Zhang, H.Q. Guo, J. van Lier, H. Kronmuller, and B.G. Shen, Appl. Phys. Lett. 72, 1110 (1998).

18. W.B. Yelon, Z. Hu, W.J. James, and G.K. Marasinghe, J. Appl. Phys. 79, 5939 (1996).

19. D.J. Branagan, M.J. Kramer, and R.W. McCallum, J. Alloys Compd. 244, 27 (1996).

20. Atlas of Crystal Structure Types for Intermetallic Phases, edited by J.L.C. Daams, P. Villars, and J.H.N. van Vucht (ASM International, Metals Park, OH, 1991).

21. International Tables for Crystallography, edited by U. Shmueli (Kluwer Academic, New York, 1993), Vol. B.

22. W.B. Yelon, IEEE Trans. Magn. 31, 3689 (1995).

23. G.K. Marasinghe, P.C. Ezekwenna, W.J. James, J.G. Long, O.A. Pringle, Z. Hu, W.B. Yelon, and F. Grandjean, J. Appl. Phys. 79, 4587 (1996).

24. G.J. Long, G.K. Marasinghe, S. Mishra, O.A. Pringle, F. Grandjean, K.H.J. Buschow, D.P. Middleton, W.B. Yelon, F. Pourian, and O. Isnard, Solid State Comm. 88, 761 (1993).

25. Z. Chen, G.C. Hadjipanayis, M. Daniel, M. Digas, A. Moukarika, and V. Papaefthymiou, J. Magn. Magn. Mater. 177-181, 1109 (1998).

26. Z. Hu and W.B. Yelon, J. Appl. Phys. 80, 6175 (1996). 